\title{
Is idiosyncratic risk ignored in asset pricing: Sri Lankan evidence?
}

\author{
Moinak Maiti ${ }^{*}$ (1)
}

\begin{abstract}
The present study focused on one of the important South Asian nations - Sri Lanka - to examine the role of idiosyncratic volatility in asset prices. A four-factor model with idiosyncratic volatility was designed for capturing the market, size, value and idiosyncratic risk yields better than Fama and French's (J Financ Econ 33:3-56, 1993) three-factor model and performance of the model. Fama-MacBeth's cross-sectional regression, residual graphs and GRS test all confirm the superiority of four-factor model over 2 three-factor models. For all MC- and IVOL-based portfolios, idiosyncratic volatility is negatively related to the expected returns and positively related for all PB-based portfolios. Finally, study findings confirm that there is a high importance for idiosyncratic volatility risk factor while considering investment decision in Colombo stock exchange. Hence, investor should compensate for holding such risk factors in the portfolio.
\end{abstract}

Keywords: Asset pricing, Idiosyncratic risk, Factor models, Fama-MacBeth'cross-sectional regression, Risk

JEL Classification: G12

\section{Introduction}

Risk is broadly classified into two groups: one systematic and another unsystematic. Systematic risk is a risk which cannot be diversified like market risk, whereas unsystematic risk can be diversified, and hence, systematic risk should be priced by the investors. Earlier studies by Sharpe [1], Lintner [2] and Mossin [3] consider only the systematic risk to derive risk return relationship and argued that investor holds well-diversified market portfolio which, in turn, diversified the idiosyncratic volatility. In reality, capital markets are more complex, and simply holding well-diversified portfolios will not automatically reduce the idiosyncratic volatility completely. In such case, if investors are not able to distinguish between systematic and unsystematic risk clearly, investors will observe underperformance in its investment decision. Merton [4] argued that investor who holds undiversified portfolio should not be compensated. Previous studies show mixed results about the importance of the idiosyncratic volatility in stock returns. As a result, it is always

\footnotetext{
*Correspondence: mmaiti@hse.ru

Department for Finance, St. Petersburg School of Economics

and Management, National Research University Higher School

of Economics, Kantemirovskaya St. 3A, Sankt Petersburg, Russia 194100
}

a topic of discussion among the researchers whether idiosyncratic volatility should be priced or not by the investors?

Malkiel and $\mathrm{Xu}[5,6]$, Goyal and Santa-Clara [7] and $\mathrm{Fu}[8]$ studies find a positive relationship between the idiosyncratic volatility and stock returns, whereas considerable number of studies by Ang et al. [9, 10], Guo and Savickas [11], Frieder and Jiang [12], Chua et al. [13] and Wagner and Winter [14] find a negative relationship between the idiosyncratic volatility and stock returns. One finding which is common in most of the above-mentioned studies is that CAPM neglects idiosyncratic volatility in asset pricing. Presently emerging capital markets are equally important like the other developed markets, and Blackrock [15] reports say that the shares of emerging markets, especially Asian markets, are increasing. Sri Lanka's Colombo stock exchange is one such important exchange that has seen significant development and foreign investment in the last decade. Colombo stock exchange is one of the important exchanges in South Asia that provides electronic trading. Considering the fact that the effect of idiosyncratic volatility of stock returns is mixed, the present study will be the maiden attempt 
to study comprehensively on Sri Lanka's Colombo stock exchange.

The present study will explicitly report how important idiosyncratic volatility is in Sri Lankan context, which is not addressed by any other previous studies. Study by Bali et al. [16] found that stock with small size tends to have more idiosyncratic volatility than big-size stocks. Second, the present study will address the same by following portfolio-based study results. Third study will deploy different designs and methodologies that are different from previous studies. Different researchers follow different frequencies and proxies for idiosyncratic volatility calculation. Daily data were used by Ang et al. [9] study, whereas Frieder and Jiang [12] study used monthly data for calculating idiosyncratic volatility. Many of the studies by Ang et al. [9] and Frieder and Jiang [12] used time series data for fixed time period, whereas Fu [8] study found that idiosyncratic volatility is time-varying. Hence, study findings based on fixed model are questionable and need dynamic check. Ang et al. $[9,10]$ used lagged realised idiosyncratic volatility as proxy, whereas Fu [8] used expected idiosyncratic volatility as proxy for idiosyncratic volatility. The present study uses Fama and French [17]based approach in calculating the idiosyncratic volatility proxy. Finally, the study uses both time series and crosssectional analysis to explore the significance of idiosyncratic volatility in asset pricing. The rest of the paper is divided into the following sections: literature review, data and methodology, empirical results, asset-pricing results, model performance test and conclusions.

\section{Literature review}

Traditional asset-pricing studies by Sharpe [1], Lintner [2] and Mossin [3] argue that unsystematic risk should not be price the investors as investors hold well-diversified market portfolio. Considerable number of studies in last few decades challenged the basic fundamental idea of not to compensate the unsystematic risk. Black and Scholes [18] and Merton [4] studies argued that increase in the stochastic volatility of the stocks or portfolios leads to increase in the value of the equity, and hence, idiosyncratic risk should be compensated by the investors. Idiosyncratic risk is a firm-specific risk, and considerable number of studies by Banz [19], Reinganum [20], Gibbons [21], Basu [22], Bhandari [23]. Ross [24], Fama and French [17], Balakrishnan and Maiti [25], Balakrishnan et al. [26], Maiti and Balakrishnan [27], Maiti [28, 29, 30], etc., proved that there are several firm-specific risks other than market risk. Campbell et al. [31] found that average total volatility increases over a period of time, whereas market volatility shows no pattern. Further study found that idiosyncratic volatility component of the total volatility factor is very important and time-varying. The study also argued that a well-diversified portfolio must contain over 50 stocks and practically idiosyncratic volatility cannot be diversified completely. A sizeable number of studies related to idiosyncratic risk have been carried out globally, and the results are mixed.

Chua et al. [13] studies found that the expected stock returns are positively related to the idiosyncratic volatility. A sizable number of studies by Jiang and Lee [32], Malkiel and Xu [6], Drew et al. [33], Huang et al. [34] and Zaremba [35] also found positive relationship between expected returns and idiosyncratic volatility. Similarly, other set of studies by Ang et al. [9, 10], Guo and Savickas [11], Frieder and Jiang [12], Chua et al. [13] and Peterson and Smedeman [36] found that idiosyncratic volatility is negatively related to the expect stock returns. Recent study by Liu and Di Iorio [37] in Australian context finds a positive relationship between the expected returns and idiosyncratic volatility. The study also finds that idiosyncratic factor is very much significant in explaining returns in both time series and cross-sectional set-up. Finally, study also finds that big stocks are systematically much riskier than the small stocks. From the above literature review, it is clear that idiosyncratic volatility is important factor in explaining the risk and return relationship. A sizeable number of studies related to idiosyncratic volatility and expected returns have been carried out on the developed markets, and as Sri Lanka is concerned, no study has been done so far related to the idiosyncratic volatility and expected returns.

\section{Data and methodology \\ Data}

Present study uses both daily and monthly data of 251 stocks listed in Colombo stock exchange for the period July 2008 to December 2016 of the following variables. Market capitalisation (MC) was used as proxy for size, $P / B$ ratio was used as proxy for value, Standard and Poor's Sri Lanka 20 index return were used as the proxy for market (Rm), and 91-day T-Bill was used as the proxy for risk-free rate (Rf). Similar to Ang et al. [9, 10] study, standard deviation of Fama and French's [17] three-factor regression residuals was used as the proxy for idiosyncratic volatility. For the same period, daily excess returns are regressed with the daily excess market ( $R m-R f)$, size (SMB) and value (LMH) factor for the whole sample period to obtain the regression residuals.

$$
R_{P t}-R_{F t}=a a+b b\left(R_{M t}-R_{F t}\right)+s s \mathrm{SMB}_{t}+l l \mathrm{LMH}_{t}+e_{t}
$$

where $R_{P t}-R_{F t}$ is the daily excess return of the stocks, $R_{M t}-R_{F t}$ is the daily excess return of the market, SMB is the daily excess return of the size risk factor, LMH is the daily excess return of the value risk factor, $s s$ and $l l$ are 
the portfolio's responsiveness to (sensitivity coefficients) SMB and LMH factors, respectively.

Idiosyncratic volatility of the stock is calculated as the standard deviation of the residual obtained from the regression of equation number 1 . Then the daily idiosyncratic volatility was converted to monthly idiosyncratic volatility (IVOL) by multiplying the daily value with the square root of number of trading days for that month.

\section{Portfolio construction}

Statman [38] argued that a well-diversified portfolio must contain at least 30 stocks, and further Campbell et al. [31] study added that in recent decades to achieve a certain level of diversification in portfolio returns, it must have more than 40 stocks. Our study sample has 251 stocks, and hence, six portfolios are formed to achieve the greater level of diversification. Using single-sorting technique, every year in the month of June $(t)$, six equalweighted portfolios are constructed based on each $\mathrm{MC}$, $P / B$, and IVOL variables. The portfolios are names as P11 to P16. Revision of portfolios ranking again done in the month of June ${ }^{1}$ next year $(t+1)$ following the same procedure and repeated up to year 2016.

\section{Mimicking risk factor construction}

Using single-sorting technique every year in the month of June $(t)$, two equal-weighted portfolios are constructed based on MC. Top 50\% stocks with high value of MC stocks are named Big $(B)$ and rest $50 \%$ names as Small $(S)$. Revision of portfolios ranking again was done in the month of June next year $(t+1)$ following the same procedure and repeated up to year 2016. Then using single-sorting technique every year in the month of June $(t)$, three value-weighted portfolios ([17] breakpoints of 30:40:30) are constructed based on each $P / B$ and IVOL variables. Top $30 \%$ stocks with high value of $P / B$ named as high $(H)$, bottom $30 \%$ stocks with less value of $P / B$ named as low $(L)$ and rest $40 \%$ named as neutral $(N)$. Similarly, top $30 \%$ stocks with high value of IVOL (Hv) named as high IVOL, bottom $30 \%$ stocks with less value of IVOL named as low IVOL (Lv) and rest $40 \%$ named as neutral (Nv). Revision of portfolios ranking again was done in the month of June next year $(t+1)$ following the same procedure and repeated up to year 2016 .

Using double-sorting technique, every year in the month of June $(t)$, six value-weighted portfolios are constructed from the cross of two MC and three $P / B$ portfolios obtained from single sort. Six portfolios are named

\footnotetext{
1 Three months lag period given, generally in Sri Lanka the financial year ends in the month of March of every year.
}

as $S / L, S / N, S / G, B / L, B / N$ and $B / G$, where $S / L$ portfolio contains 'small size and low value stocks' and $B / G$ portfolio contains 'big size and high value stocks'. Revision of portfolios ranking again was done in the month of June next year $(t+1)$ following the same procedure and repeated up to year 2016. Then using double-sorting technique, every year in the month of June $(t)$, six valueweighted portfolios are constructed from the cross of two MC and three IVOL portfolios obtained from single sort. Six portfolios are named as $S / \mathrm{Lv}, S / \mathrm{Nv}, S / \mathrm{Gv}, B / \mathrm{Lv}$, $B / \mathrm{Nv}$ and $\mathrm{B} / \mathrm{Gv}$, where $S / \mathrm{Lv}$ portfolio contains 'small size and low idiosyncratic volatility stocks' and $B / G$ portfolio contains 'big size and high idiosyncratic volatility stocks'. Revision of portfolios ranking again was done in the month of June next year $(t+1)$ following the same procedure and repeated up to year 2016.

Present study uses three risk-mimicking portfolios SMB (size), LMH (value) and LvMHv (idiosyncratic volatility), and they are estimated as described below: ${ }^{2}$

$$
\begin{aligned}
& \mathrm{SMB}=(S / L+S / M+S / H) / 3-(B / L+B / M+B / H) / 3 \\
& \mathrm{LMH}=(S / L+B / L) / 2-(S / H+B / H) / 2 \\
& \mathrm{LvMHv}=(S / \mathrm{Lv}+B / \mathrm{Lv}) / 2-(S / \mathrm{Hv}+B / \mathrm{Hv}) / 2
\end{aligned}
$$

The present study uses four regressions as explained below:

\section{Fama-French three-factor model}

$$
R_{P t}-R_{F t}=a+b\left(R_{M t}-R_{F t}\right)+s \mathrm{SMB}_{t}+l \mathrm{LMH}_{t}+e_{t}
$$

where SMB mimics size risk factor, LMH mimics value risk factor, $s$ and $l$ are the sensitivity coefficients of SMB and LMH factors.

\section{Three factor model with idiosyncratic volatility}

$$
R_{P t}-R_{F t}=a+b\left(R_{M t}-R_{F t}\right)+s \mathrm{SMB}_{t}+v \mathrm{LvMHv}_{t}+e_{t}
$$

where SMB mimics size risk factor, LMH mimics idiosyncratic volatility risk factor, $s$ and $v$ are the sensitivity coefficients of SMB and LvMHv factors.

\footnotetext{
${ }^{2}$ Fama and French [17] estimate HML, which stands for high minus low, and mimics the risk factor associated with company value. They form HML using $\mathrm{BE} / \mathrm{ME}$ while this study estimates $\mathrm{LMH}$ (See [25]) using P/B ratio which is inversely related to $\mathrm{BE} / \mathrm{ME}$ as $\mathrm{BE} / \mathrm{ME}$ ratios for the sample companies are not directly available in the data source. Hence, our interpretations of the results of value factor are mirror image to those of FFTF model [17].
} 
Table 1 Descriptive statistics for the independent variables

\begin{tabular}{lllll}
\hline & Rm & SMB & LMH & LvMHv \\
\hline Mean returns & 0.006 & 0.003 & 0.001 & 0.001 \\
SD & 0.053 & 0.011 & 0.011 & 0.009
\end{tabular}

Four-factor model with market, size, value, and idiosyncratic volatility

$$
\begin{aligned}
R_{P t}-R_{F t}= & a+b\left(R_{M t}-R_{F t}\right)+s \mathrm{SMB}_{t} \\
& +l \mathrm{LMH}_{t}+v \mathrm{LvMHv}_{t}+e_{t}
\end{aligned}
$$

\section{Fama-MacBeth's cross-sectional regression} It is a step regression as explained below

Step 1
Table 3 Correlation matrix for explanatory variables

\begin{tabular}{lllll}
\hline & Rm & SMB & LMH & LvMHv \\
\hline Rm & 1 & & & \\
SMB & -0.056 & 1 & & \\
LMH & -0.147 & -0.092 & 1 & \\
LVMHV & 0.013 & -0.196 & 0.269 & 1 \\
\hline
\end{tabular}

weakly negatively to the other variables. Size is negatively related to value to idiosyncratic volatility factor. Value and idiosyncratic volatility factor are positively related.

\section{Empirical results}

Radar graph in Fig. 1 shows the average mean excess return pattern of portfolios based on MC, PB and IVOL. Portfolio P11 shows higher average mean excess return in case of $\mathrm{MC}$ - and $P / B$-based portfolios, whereas P16 of

$$
\begin{aligned}
& \left(R_{P t}-R_{F t}\right)_{1, t}=a+b_{1, \text { beta }}\left(R_{M t}-R_{F t}\right)_{1, t}+s_{1, \mathrm{smb}} \mathrm{SMB}_{1, t}+l_{1, t} \mathrm{LMH}_{1, t}+v_{1, t} \mathrm{LvMHv}_{1, t}+e_{1, t} \\
& \left(R_{P t}-R_{F t}\right)_{2, t}=a+b_{2, \text { beta }}\left(R_{M t}-R_{F t}\right)_{2, t}+s_{2, \mathrm{smb}_{2, t}} \mathrm{SMB}_{2, t}+l_{2, t} \mathrm{LMH}_{2, t}+v_{2, t} \mathrm{LvMHv}_{2, t}+e_{2, t} \\
& \quad: \\
& \quad \\
& \left(R_{P t}-R_{F t}\right)_{n, t}=a+b_{n, \text { beta }}\left(R_{M t}-R_{F t}\right)_{n, t}+s_{\mathrm{smb}, t} \mathrm{SMB}_{n, t}+l_{\mathrm{lmb}_{, t}} \mathrm{LMH}_{n, t}+v_{n, t} \mathrm{LvMHv}_{n, t}+e_{n, t}
\end{aligned}
$$

Step 2

$$
\begin{aligned}
R_{P t}-R_{F t}= & \lambda_{0}+\lambda_{\mathrm{rm}}\left(R_{M t}-R_{F t}\right)+\lambda_{\mathrm{smb}} \mathrm{SMB}_{t} \\
& +\lambda_{\mathrm{lmh}} \mathrm{LMH}_{t}+\lambda_{\mathrm{ivol}} \mathrm{LvMHv}_{t}+e_{t}
\end{aligned}
$$

\section{Explanatory variables}

Table 1 shows descriptive statistics for the explanatory variables. Average mean excess returns for all the variables are comparatively low and among all average excess market return outperformed others. Average mean excess market return is $0.7 \%(t=2.281)$; size premium is $0.3 \%(t=2.754)$; both value and idiosyncratic premium are $0.2 \%$. Average return pattern reveals that investor will gain moderate return by aligning their investment strategies to market and size. Table 2 shows year-wise average monthly idiosyncratic volatility that prevails in Colombo stock exchange stocks.

Correlation between the explanatory variables is shown in Table 3. Except idiosyncratic volatility market is related

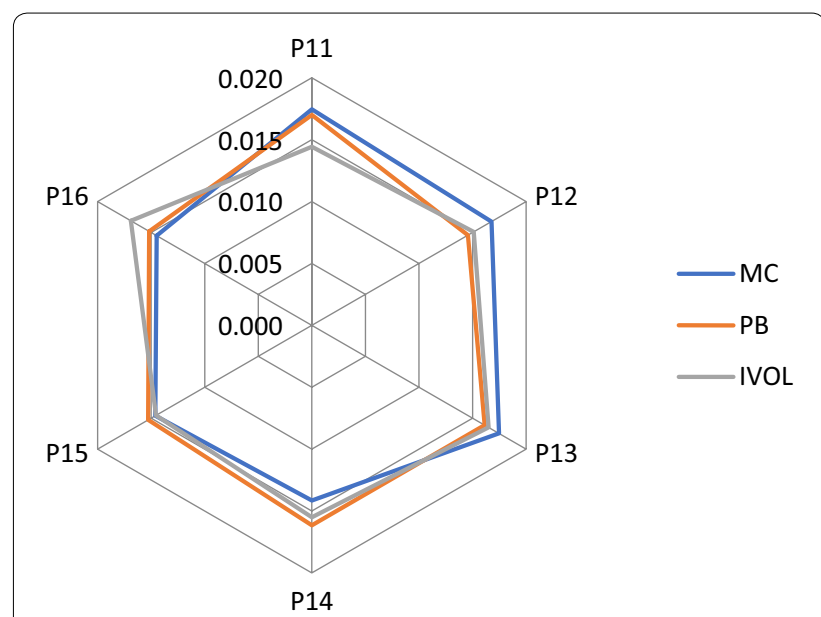

Fig. 1 Radar graph shows mean excess returns of six portfolios formed on MC, PB and IVOL

Table 2 Year-wise monthly IVOL

Average monthly IVOL

\begin{tabular}{lllllllll}
\hline 2008 & 2009 & 2010 & 2011 & 2012 & 2013 & 2014 & 2015 & 016 \\
\hline 0.295 & 0.245 & 0.443 & 0.365 & 0.250 & 0.189 & 0.166 & 0.166
\end{tabular}


Table 4 Summary statistics of six portfolios formed on MC, PB and IVOL

\begin{tabular}{|c|c|c|c|c|c|c|c|c|c|}
\hline \multirow[t]{2}{*}{ Portfolio } & \multicolumn{3}{|l|}{ MC } & \multicolumn{3}{|l|}{ PB } & \multicolumn{3}{|l|}{ IVOL } \\
\hline & $\begin{array}{l}\text { Mean excess } \\
\text { returns }\end{array}$ & SD & $T$-statistics & $\begin{array}{l}\text { Mean excess } \\
\text { returns }\end{array}$ & SD & $T$-statistics & $\begin{array}{l}\text { Mean excess } \\
\text { returns }\end{array}$ & SD & $T$-statistics \\
\hline P11 & 0.017 & 0.109 & 1.566 & 0.017 & 0.106 & 1.559 & 0.014 & 0.107 & 1.310 \\
\hline P12 & 0.017 & 0.108 & 1.518 & 0.015 & 0.106 & 1.333 & 0.015 & 0.108 & 1.369 \\
\hline P13 & 0.017 & 0.106 & 1.611 & 0.016 & 0.107 & 1.476 & 0.016 & 0.108 & 1.490 \\
\hline P14 & 0.014 & 0.108 & 1.281 & 0.016 & 0.105 & 1.502 & 0.016 & 0.105 & 1.436 \\
\hline P15 & 0.015 & 0.105 & 1.351 & 0.015 & 0.108 & 1.373 & 0.015 & 0.105 & 1.349 \\
\hline P16 & 0.014 & 0.107 & 1.316 & 0.015 & 0.109 & 1.363 & 0.017 & 0.109 & 1.515 \\
\hline
\end{tabular}

Table 5 Regression results of Fama-French's three-factor model for six portfolios $R_{P t}-R_{F t}=a+b\left(R_{M t}-R_{F t}\right)+$ $s \mathrm{SMB}_{t}+I \mathrm{LMH}_{t}+e_{t}$

\begin{tabular}{|c|c|c|c|c|c|c|c|c|c|c|c|c|}
\hline & \multicolumn{6}{|l|}{ MC } & \multicolumn{6}{|l|}{ PB } \\
\hline & P11 & P12 & P13 & P14 & P15 & P16 & P11 & P12 & P13 & P14 & P15 & P16 \\
\hline c & 0.003 & 0.003 & 0.004 & 0.003 & 0.003 & 0.003 & 0.004 & 0.002 & 0.004 & 0.004 & 0.003 & 0.002 \\
\hline $\mathrm{Rm}$ & 2.001 & 2.005 & 1.958 & 1.991 & 1.944 & 1.991 & 1.991 & 1.981 & 1.971 & 1.936 & 1.995 & 1.993 \\
\hline SMB & 0.619 & 0.578 & 0.490 & -0.268 & -0.218 & -0.214 & 0.544 & 0.263 & 0.049 & 0.018 & -0.120 & 0.099 \\
\hline LMH & -0.380 & 0.063 & -0.079 & -0.153 & -0.265 & -0.068 & 0.650 & 0.061 & -0.168 & -0.253 & -0.327 & -0.754 \\
\hline tc & 1.535 & 1.463 & 1.963 & 1.304 & 1.600 & 1.527 & 1.786 & 0.850 & 1.878 & $2.055^{*}$ & 1.470 & 1.298 \\
\hline tr & $5.664^{*}$ & $5.412^{*}$ & $5.756^{*}$ & $5.047^{*}$ & $5.837^{*}$ & $6.194^{*}$ & $5.836^{*}$ & $5.142^{*}$ & $5.378^{*}$ & $5.283^{*}$ & $5.552^{*}$ & $6.872^{*}$ \\
\hline ts & $3.228^{*}$ & $3.291^{*}$ & $2.665^{*}$ & -1.554 & -1.263 & -1.335 & $3.085^{*}$ & 1.505 & 0.274 & 0.104 & -0.626 & 0.620 \\
\hline tl & $-2.072^{*}$ & 0.376 & -0.449 & -0.925 & -1.610 & -0.441 & $3.849^{*}$ & 0.363 & -0.979 & -1.500 & -1.781 & -4.957 \\
\hline \multirow[t]{3}{*}{$R^{2}$} & 0.967 & 0.972 & 0.968 & 0.973 & 0.972 & 0.976 & 0.971 & 0.972 & 0.970 & 0.970 & 0.967 & 0.977 \\
\hline & & \multicolumn{11}{|l|}{ IVOL } \\
\hline & & P11 & & P12 & & P13 & & P14 & & P15 & & P16 \\
\hline c & & 0.002 & & 0.003 & & 0.004 & & 0.003 & & 0.001 & & 0.004 \\
\hline $\mathrm{Rm}$ & & 1.997 & & 1.996 & & 1.997 & & 1.951 & & 1.950 & & 2.008 \\
\hline SMB & & -0.159 & & 0.097 & & -0.013 & & 0.371 & & 0.393 & & 0.223 \\
\hline LMH & & -0.063 & & 0.123 & & -0.122 & & 0.124 & & -0.171 & & -0.281 \\
\hline tc & & 1.453 & & 1.207 & & $2.018^{*}$ & & 1.141 & & 0.729 & & 1.835 \\
\hline $\operatorname{tr}$ & & $6.885^{*}$ & & $5.827^{*}$ & & $5.658^{*}$ & & $4.996^{*}$ & & $5.585^{*}$ & & $5.768^{*}$ \\
\hline ts & & -1.030 & & 0.508 & & -0.069 & & 1.878 & & $2.307^{*}$ & & 1.210 \\
\hline tl & & -0.424 & & 0.676 & & -0.693 & & 0.654 & & -1.049 & & -1.586 \\
\hline$R^{2}$ & & 0.978 & & 0.967 & & 0.969 & & 0.963 & & 0.972 & & 0.969 \\
\hline
\end{tabular}

$s$ and $/$ are the sensitivity coefficients of SMB and LMH factors

*Significant at $5 \%$ level

IVOL-based portfolios shows higher average mean excess return than other portfolios.

Further from Table 4, it is observed that average return pattern falls from P11 (small-size) portfolio to P16 (bigsize) portfolio in case of MC-based portfolio. These decreasing pattern of average mean excess return from $\mathrm{P} 11(1.7 \%, t=1.566)$ to $\mathrm{P} 16(1.4 \%, t=1.316)$ is known as size effect. Similarly, average return pattern falls from P11 (low $P / B$ ) portfolio to P16 (high $P / B$ ) portfolio in case of $P / B$-based portfolio. These decreasing pattern of average mean excess return from P11 $(1.7 \%, t=1.559)$ to $\mathrm{P} 16(1.5 \%, t=1.363)$ is known as value effect, and it is similar to Maiti $[28,29]$ study in Indian context. The size and value effect pattern are quite similar to Balakrishnan and Maiti [25] study in Indian context. Average return pattern increases from P11 (low IVOL) portfolio to P16 (high IVOL) portfolio in case of IVOL-based portfolio confirms weak idiosyncratic volatility effect. 


\section{Results and discussion}

Asset-pricing results

Fama-French's Three-factor regressions (market, size and value)

Any good asset-pricing model must able to capture all alpha values equal to zero. Results of Fama-French's three-factor regressions are shown in Table 5. Portfolio P11 (first portfolio) is well captured by the model for MC-, $P / B$ - and IVOL-based portfolios. Further result shows one portfolio of $\mathrm{PB}$ (P14) and one portfolio of IVOL (P13) are significant at 5\% level. Market (Rm) coefficients of all portfolios based on $\mathrm{MC}, P / B$ and IVOL are highly positive and significant. Size (SMB) coefficients are positive for small-size portfolios and become negative towards big-size portfolios in case of MC-based portfolios, whereas SMB coefficients are mostly positive in case of $P / B$ - and IVOL-based portfolios. SMB coefficients of 3 MC- (P11, P12 and P13), 1 PB- (P11) and 1 IVOL (P15)based portfolios are found to be significant. Value (LMH) coefficients are mostly negative for $\mathrm{MC}$-, $P / B$ - and IVOLbased portfolios. First two portfolios of PB-based portfolios have positive LMH coefficient and are significant, whereas LMH coefficient changes its sign towards high $P / B$ portfolios. LMH coefficients of $1 \mathrm{MC}$ - (P11) and $1 \mathrm{~PB}$ (P11)-based portfolios are significant. Average alpha value and R-square values are 0.003 and $97 \%$ for FamaFrench's three-factor regressions. The study results do not support the Fama and French [17] findings in US context.

\section{Three factor regressions (market, size and idiosyncratic volatility)}

Portfolio P11 (first portfolio) is well captured by the model for MC-, $P / B$ - and IVOL-based portfolios. Further result shows that one portfolio of $\mathrm{PB}(\mathrm{P} 14)$ and one portfolio of IVOL (P16) are significant at 5\% level. It implies that high idiosyncratic volatility stocks portfolio is not captured by the model. Market (Rm) coefficients of all portfolios based on $\mathrm{MC}, P / B$ and IVOL are highly positive and significant. Size (SMB) coefficients are positive for small-size portfolios and become negative towards big-size portfolios in case of MC-based portfolios, whereas SMB coefficients are mostly positive in case of $P / B$ - and IVOL-based portfolios. Value (LMH) coefficients are mostly negative for $M C$-, $P / B$ - and IVOL-based portfolios. SMB coefficients of $3 \mathrm{MC}$-based (P11, P12 and $\mathrm{P} 13)$ and $1 \mathrm{~PB}$-based (P11) portfolios found to be significant. In most of the cases, IVOL coefficient is found to be positive and is significant for 4 IVOL (P11, P12, P13 and P16), $1 \mathrm{MC}$ (P12) and $1 \mathrm{~PB}$ (P11) portfolios, respectively. First four portfolios of IVOL-based portfolios have positive IVOL coefficient, and IVOL coefficient changes its sign towards high IVOL portfolios. Average alpha value and R-square values are 0.003 and $97 \%$ for three-factor regressions with idiosyncratic volatility.

\section{Four-factor regression results (market, size, value and idiosyncratic volatility)}

Portfolio P11 (first portfolio) is well captured by the model for MC-, $P / B$ - and IVOL-based portfolios. Further result shows that one portfolio of $\mathrm{PB}$ (P14) and one portfolio of IVOL (P16) are significant at 5\% level. It implies that high idiosyncratic volatility stock portfolio is not captured by the model. Market ( $\mathrm{Rm}$ ) coefficients of all portfolios based on $\mathrm{MC}, P / B$ and IVOL are highly positive and significant. Size (SMB) coefficients are positive for smallsize portfolios and become negative towards big-size portfolios in case of MC-based portfolios, whereas SMB coefficients are mostly positive in case of $P / B$ - and IVOLbased portfolios. Value (LMH) coefficients are mostly negative for MC-, $P / B$ - and IVOL-based portfolios. First portfolio of IVOL portfolios SMB coefficient is negative that implies that among low idiosyncratic volatility stocks big stocks have less idiosyncratic risk. SMB coefficients of 3 MC-based (P11, P12 and P13), 1 PB-based (P11) and 1 IVOL-based (P15) portfolios found to be significant. In most of the cases, IVOL coefficient found to be positive and is significant for 4 IVOL (P11, P12, P13 and P16) and $1 \mathrm{MC}$ (P12) portfolios, respectively. First four portfolios of IVOL-based portfolios have positive IVOL coefficient and IVOL coefficient changes its sign towards high IVOL portfolios. Average alpha value and $R^{2}$ values are 0.003 and $97 \%$ for four-factor regressions.

From the above results, it is concluded that both threefactor models yield similar results. Four-factor models do not improve the results much from both of the three-factor models, but investors who are interested in idiosyncratic volatility premium may consider four-factor models with $P / B$-based portfolios for better results. Study results shows that idiosyncratic volatility is related to the expected returns of all MC-, $P / B$ - and IVOL-based portfolios. Investor who ranks their portfolios based on IVOL must be careful with the high idiosyncratic volatility portfolios (Tables 6,7 ).

\section{Fama-MacBeth's cross-sectional regression results}

Then study runs Fama and MacBeth's [39] cross-sectional regression to verify the importance of idiosyncratic volatility in explaining portfolios expected returns, and results are shown in Table 8 . All the models used in the study are well accepted by the Fama-MacBeth's crosssectional regression test. Fama-MacBeth's cross-sectional regression test also confirms that idiosyncratic volatility is significantly related to the portfolio expected returns. Fama-MacBeth's cross-sectional regression of two-factor, three-factor, and four-factor model with idiosyncratic 
Table 6 Regression results of three-factor model with idiosyncratic volatility for six portfolios $R_{P t}-R_{F t}=a+b\left(R_{M t}-R_{F t}\right)$ $+s \mathrm{SMB}_{t}+v \mathrm{LvMHv}_{t}+e_{t}$

\begin{tabular}{|c|c|c|c|c|c|c|c|c|c|c|c|c|}
\hline & \multicolumn{6}{|l|}{ MC } & \multicolumn{6}{|l|}{ PB } \\
\hline & P11 & P12 & P13 & P14 & P15 & P16 & P11 & P12 & P13 & P14 & P15 & P16 \\
\hline c & 0.003 & 0.003 & 0.004 & 0.002 & 0.003 & 0.003 & 0.003 & 0.002 & 0.004 & 0.004 & 0.003 & 0.002 \\
\hline $\mathrm{Rm}$ & 2.014 & 2.003 & 1.961 & 1.996 & 1.953 & 1.993 & 1.970 & 1.979 & 1.977 & 1.944 & 2.006 & 2.017 \\
\hline $\mathrm{SMB}$ & 0.642 & 0.648 & 0.527 & -0.240 & -0.177 & -0.166 & 0.548 & 0.280 & 0.068 & 0.044 & -0.063 & 0.180 \\
\hline LvMHv & -0.112 & 0.476 & 0.180 & 0.075 & 0.076 & 0.258 & 0.458 & 0.147 & 0.004 & -0.006 & 0.142 & 0.008 \\
\hline tc & 1.512 & 1.376 & 1.917 & 1.272 & 1.547 & 1.461 & 1.600 & 0.814 & 1.859 & $2.019^{*}$ & 1.402 & 1.121 \\
\hline $\operatorname{tr}$ & $5.469^{*}$ & $5.490^{*}$ & $5.560^{*}$ & $5.626^{*}$ & $5.994^{*}$ & $6.476^{*}$ & $5.988^{*}$ & $5.840^{*}$ & $5.879^{*}$ & $5.488^{*}$ & $5.647^{*}$ & $5.334^{*}$ \\
\hline ts & $3.227^{*}$ & $3.730^{*}$ & $2.834^{*}$ & -1.365 & -1.001 & -1.026 & $2.902^{*}$ & 1.583 & 0.370 & 0.245 & -0.317 & 0.991 \\
\hline tv & -0.459 & $2.244^{*}$ & 0.794 & 0.349 & 0.350 & 1.307 & $1.983^{*}$ & 0.681 & 0.019 & -0.027 & 0.590 & 0.035 \\
\hline \multirow[t]{3}{*}{$R^{2}$} & 0.966 & 0.973 & 0.968 & 0.973 & 0.971 & 0.977 & 0.967 & 0.972 & 0.970 & 0.969 & 0.966 & 0.971 \\
\hline & & \multicolumn{11}{|l|}{ IVOL } \\
\hline & & P11 & & P12 & & P13 & & P14 & & P15 & & P16 \\
\hline$c$ & & 0.002 & & 0.002 & & 0.004 & & 0.002 & & 0.001 & & 0.004 \\
\hline $\mathrm{Rm}$ & & 1.998 & & 1.992 & & 2.001 & & 1.947 & & 1.955 & & 2.017 \\
\hline$S M B$ & & -0.078 & & 0.200 & & 0.073 & & 0.384 & & 0.394 & & 0.161 \\
\hline LvMHv & & 0.462 & & 0.727 & & 0.456 & & 0.167 & & -0.110 & & -0.576 \\
\hline tc & & 1.355 & & 1.093 & & 1.936 & & 1.105 & & 0.747 & & $2.006^{*}$ \\
\hline tr & & $6.767^{*}$ & & $5.061^{*}$ & & $5.446^{*}$ & & $4.472^{*}$ & & $5.152^{*}$ & & $5.802^{*}$ \\
\hline ts & & -0.517 & & 1.089 & & 0.400 & & 1.919 & & $2.267^{*}$ & & 0.879 \\
\hline$t v$ & & $2.494^{*}$ & & $3.240^{*}$ & & $2.038^{*}$ & & 0.681 & & -0.520 & & $-2.569^{*}$ \\
\hline$R^{2}$ & & 0.980 & & 0.970 & & 0.970 & & 0.963 & & 0.972 & & 0.971 \\
\hline
\end{tabular}

$s$ and $v$ are the sensitivity coefficients of SMB and iVOL factors

*Significant at $5 \%$ level

volatility factor found that idiosyncratic volatility is negatively related to the expected portfolio returns for MC- and IVOL-based portfolios, whereas idiosyncratic volatility is positively related to the expected portfolio returns for PBbased portfolio. Market return is also important factor that explains risk return relationship, and it is related negatively to the excepted portfolio returns for all MC- and PB-based portfolios, whereas it is positive for IVOL-based portfolios, and findings are similar to Liu and Di Iorio [37] findings in Australian context. Fama-MacBeth's cross-sectional regression confirms that three-factor model with idiosyncratic volatility is equally significant as Fama-French's three-factor model in explaining risk return relationship. Finally, higher R-square value and F-Statistics value of four-factors Fama-MacBeth's cross-sectional regression results confirm its superiority over two of the three-factor models used in the study.

\section{Residual graphs}

Residual graphs of first portfolio (P11) of MC, PB and IVOL portfolios for different factor models are shown in Fig. 2. A model is said to be a good model fit if its residual is closer to zero or if it is zero. Not much significant difference was observed in the residual graphs of 2 threefactor models used in the study. Residual graphs for fourfactor regressions state that the higher peaks reduced to much greater extent than both the three-factor models. Results of residual graphs again confirm the superiority of four-factor model over the 2 three-factor models.

\section{Model performance test}

Regression intercepts and residual graphs are not always good in measuring the performance of the model, and hence the present study uses GRS test [40] to test the model performance. GRS model performance test results for all factor models are shown in Table 9. Except for PBbased portfolios, all factor models are passed by GRS test. The study results do support the Fama and French's [17] findings in US context for MC- and IVOL-based portfolios. Four-factor models show comparatively higher proportion of the potential efficiency than other two-factor models.

\section{Conclusion}

Due to high transaction cost and incomplete information, investors generally does not hold well-diversified portfolio, and as a result, idiosyncratic volatility associated with 
Table 7 Regression results of four-factor model for six portfolios $R_{P t}-R_{F t}=a+b\left(R_{M t}-R_{F t}\right)+s S_{M B}+$ I $\mathrm{LMH}_{t}+\mathrm{v} \mathrm{LvMHv}_{t}+e_{t}$

\begin{tabular}{|c|c|c|c|c|c|c|c|c|c|c|c|c|}
\hline & \multicolumn{6}{|l|}{ MC } & \multicolumn{6}{|l|}{ PB } \\
\hline & P11 & P12 & P13 & P14 & P15 & P16 & P11 & P12 & P13 & P14 & P15 & P16 \\
\hline c & 0.003 & 0.003 & 0.004 & 0.002 & 0.003 & 0.003 & 0.003 & 0.002 & 0.004 & 0.004 & 0.003 & 0.002 \\
\hline $\mathrm{Rm}$ & 2.001 & 2.002 & 1.957 & 1.990 & 1.943 & 1.989 & 1.989 & 1.980 & 1.971 & 1.935 & 1.993 & 1.991 \\
\hline SMB & 0.622 & 0.646 & 0.520 & -0.249 & -0.193 & -0.173 & 0.579 & 0.281 & 0.058 & 0.030 & -0.083 & 0.137 \\
\hline $\mathrm{LMH}$ & -0.384 & -0.035 & -0.124 & -0.180 & -0.301 & -0.128 & 0.598 & 0.033 & -0.181 & -0.271 & -0.381 & -0.811 \\
\hline LvMHv & 0.018 & 0.488 & 0.222 & 0.136 & 0.177 & 0.301 & 0.256 & 0.136 & 0.065 & 0.085 & 0.271 & 0.281 \\
\hline tc & 1.520 & 1.366 & 1.906 & 1.263 & 1.549 & 1.451 & 1.722 & 0.811 & 1.850 & $2.021^{*}$ & 1.407 & 1.224 \\
\hline $\operatorname{tr}$ & $5.336^{*}$ & $5.432^{*}$ & $5.635^{*}$ & $5.775^{*}$ & $5.643^{*}$ & $6.457^{*}$ & $5.821^{*}$ & $5.872^{*}$ & $5.046^{*}$ & $5.964^{*}$ & $5.516^{*}$ & $6.061^{*}$ \\
\hline ts & $3.173^{*}$ & $3.695^{*}$ & $2.787^{*}$ & -1.418 & -1.101 & -1.065 & $3.240^{*}$ & 1.583 & 0.318 & 0.167 & -0.424 & 0.856 \\
\hline tl & $-2.008^{*}$ & -0.203 & -0.678 & -1.049 & -1.760 & -0.811 & $3.427^{*}$ & 0.192 & -1.014 & -1.539 & $-2.009^{*}$ & -5.171 \\
\hline tv & 0.072 & $2.208^{*}$ & 0.941 & 0.610 & 0.799 & 1.471 & 1.133 & 0.604 & 0.282 & 0.374 & 1.102 & 1.384 \\
\hline \multirow[t]{3}{*}{$R^{2}$} & 0.967 & 0.973 & 0.968 & 0.973 & 0.972 & 0.977 & 0.971 & 0.972 & 0.970 & 0.970 & 0.967 & 0.978 \\
\hline & & \multicolumn{11}{|l|}{ IVOL } \\
\hline & & P11 & & P12 & & P13 & & P14 & & P15 & & P16 \\
\hline$c$ & & 0.002 & & 0.002 & & 0.004 & & 0.002 & & 0.001 & & 0.004 \\
\hline $\mathrm{Rm}$ & & 1.993 & & 1.991 & & 1.993 & & 1.950 & & 1.950 & & 2.011 \\
\hline SMB & & -0.087 & & 0.199 & & 0.061 & & 0.389 & & 0.385 & & 0.152 \\
\hline LMH & & -0.167 & & -0.024 & & -0.229 & & 0.097 & & -0.160 & & -0.177 \\
\hline LvMHv & & 0.518 & & 0.736 & & 0.534 & & 0.134 & & -0.057 & & -0.517 \\
\hline tc & & 1.347 & & 1.085 & & 1.932 & & 1.104 & & 0.739 & & $1.997^{*}$ \\
\hline $\operatorname{tr}$ & & $6.854^{*}$ & & $5.068^{*}$ & & $5.747^{*}$ & & $4.738^{*}$ & & $5.258^{*}$ & & $5.945^{*}$ \\
\hline ts & & -0.575 & & 1.075 & & 0.335 & & 1.934 & & $2.214^{*}$ & & 0.827 \\
\hline tl & & -1.127 & & -0.135 & & -1.286 & & 0.491 & & -0.940 & & -0.986 \\
\hline$t v$ & & $2.705^{*}$ & & $3.146^{*}$ & & $2.310^{*}$ & & 0.527 & & -0.257 & & $-2.224^{*}$ \\
\hline$R^{2}$ & & 0.980 & & 0.970 & & 0.971 & & 0.963 & & 0.972 & & 0.971 \\
\hline
\end{tabular}

$s, I$ and $v$ are the sensitivity coefficients of SMB, LMH and iVOL factors

*Significant at $5 \%$ level

the investment does not diversify completely. This signifies the importance of idiosyncratic volatility in investment decision, and investors should compensate for holding idiosyncratic risk. The present study in Sri Lankan contest evaluates the role of idiosyncratic volatility in pricing Colombo stock exchange in both time series and crosssectional set-up for a period of July 2008 to December 2016. The study result shows that IVOL-based investment strategy will yield comparatively less average returns than market-, size- and value-based investment strategies. Idiosyncratic volatility risk factor is positively weakly correlated with the market risk and size risk factors, whereas negatively weakly correlated with the value risk factor. Average portfolio means excess return pattern based on $\mathrm{MC}, \mathrm{PB}$ and IVOL that shows weak size, value and idiosyncratic volatility effects in Colombo stock exchange portfolios.

Asset-pricing results show that both Fama-French's three-factor model and three-factor model with idiosyncratic volatility factor yield similar results. Hence, investors may align their investment decision based on market and size along with value or idiosyncratic volatility factor as both will yield similar results. However, four-factor model yields comparatively better results than 2 three-factor models as some of the information which is omitted by the three-factor models is captured by the four-factor model. Times series regressions with different factor model yield almost similar results, but cross-sectional set-up estimates give more vivid view of the risk variables. For all MC- and IVOL-based portfolios idiosyncratic volatility is negatively related to the expected returns, whereas it is positively related to all PB-based portfolios. This implies that high idiosyncratic risk prevails in the small size, big $P / B$ value and low IVOL stocks of the Colombo stock exchanges stocks. Further Fama-MacBeth cross-sectional regression confirms that idiosyncratic volatility captures information omitted by the Fama-French three-factor model, and study findings are similar to Liu and 
Table 8 Fama-Macbeth's cross-sectional regression result

\begin{tabular}{|c|c|c|c|c|c|c|c|c|c|c|}
\hline \multicolumn{2}{|c|}{ Parameters } & \multicolumn{2}{|c|}{$\lambda_{0}$} & \multicolumn{2}{|l|}{$\lambda_{\mathrm{rm}}$} & \multicolumn{2}{|l|}{$\lambda_{\text {Ivmhv }}$} & Adjusted $R^{2}$ & \multicolumn{2}{|c|}{$F$-statistics( $P$ value) } \\
\hline \multicolumn{11}{|c|}{ Two factors with market and idiosyncratic volatility } \\
\hline \multirow{3}{*}{ MC } & Mean & \multicolumn{2}{|c|}{0.025} & -0.005 & & \multicolumn{2}{|c|}{-0.004} & 23.8 & 0.468 & 0.665 \\
\hline & SD & \multicolumn{2}{|c|}{0.314} & 0.166 & & \multicolumn{2}{|c|}{0.024} & & & \\
\hline & T-statistics & \multicolumn{2}{|c|}{0.787} & -0.269 & & \multicolumn{2}{|c|}{-1.475} & & & \\
\hline \multirow[t]{3}{*}{ PB } & Mean & \multicolumn{2}{|c|}{0.049} & -0.017 & & \multicolumn{2}{|c|}{0.002} & 44.2 & 1.187 & 0.417 \\
\hline & SD & \multicolumn{2}{|c|}{0.316} & 0.168 & & \multicolumn{2}{|c|}{0.042} & & & \\
\hline & $T$-statistics & \multicolumn{2}{|c|}{1.498} & -0.966 & & 0.530 & & & & \\
\hline IVOL & Mean & & & 0.018 & & -0.00 & & 42.1 & 1.091 & 0.441 \\
\hline & SD & & & 0.181 & & 0.010 & & & & \\
\hline & $T$-statistics & & & 0.941 & & -0.83 & & & & \\
\hline & Parameters & $\lambda_{0}$ & $\lambda_{\mathrm{rm}}$ & & $\lambda_{\text {smb }}$ & & $\lambda_{\operatorname{lmh}}$ & Adjusted $R^{2}$ & $\begin{array}{l}\text { F-statist } \\
\text { value) }\end{array}$ & \\
\hline Fama & h three factor & & & & & & & & & \\
\hline$M C$ & Mean & 0.028 & -0.006 & & 0.005 & & 0.005 & 41.1 & 0.466 & 0.736 \\
\hline & SD & 0.323 & 0.170 & & 0.043 & & 0.032 & & & \\
\hline & T-statistics & 0.838 & -0.365 & & 1.214 & & 1.516 & & & \\
\hline PB & Mean & 0.062 & -0.023 & & 0.001 & & 0.001 & 66 & 1.292 & 0.464 \\
\hline & SD & 0.396 & 0.207 & & 0.009 & & 0.012 & & & \\
\hline & T-statistics & 1.526 & -1.108 & & 0.966 & & 0.519 & & & \\
\hline IVOL & Mean & 0.008 & 0.004 & & -0.004 & & -0.001 & 44.2 & 0.527 & 0.706 \\
\hline & SD & 0.504 & 0.259 & & 0.035 & & 0.042 & & & \\
\hline & $T$-statistics & 0.155 & 0.164 & & -1.001 & & -0.124 & & & \\
\hline & Parameters & $\lambda_{0}$ & $\lambda_{\mathrm{rm}}$ & & $\lambda_{\text {smb }}$ & & $\lambda_{\text {Ivmhv }}$ & Adjusted $R^{2}$ & $\begin{array}{l}F \text {-statist } \\
\text { value) }\end{array}$ & \\
\hline Threet & s with idiosyncratic & Dlatility & & & & & & & & \\
\hline$M C$ & Mean & 0.035 & -0.011 & & 0.010 & & -0.003 & 80.8 & 2.809 & 0.273 \\
\hline & SD & 0.315 & 0.167 & & 0.037 & & 0.024 & & & \\
\hline & T-statistics & 1.091 & -0.617 & & $2.573^{*}$ & & -1.357 & & & \\
\hline PB & Mean & 0.047 & -0.016 & & 0.001 & & 0.002 & 62.5 & 1.110 & 0.506 \\
\hline & SD & 0.316 & 0.168 & & 0.008 & & 0.062 & & & \\
\hline & T-statistics & 1.461 & -0.926 & & 0.966 & & 0.242 & & & \\
\hline IVOL & Mean & 0.003 & 0.007 & & -0.002 & & -0.001 & 43.9 & 0.521 & 0.709 \\
\hline & SD & 0.693 & 0.346 & & 0.069 & & 0.012 & & & \\
\hline & $T$-statistics & 0.038 & 0.192 & & -0.345 & & -0.585 & & & \\
\hline & Parameters & $\lambda_{0}$ & $\lambda_{\mathrm{rm}}$ & $\lambda_{\text {smb }}$ & & $\lambda_{\operatorname{lmh}}$ & $\lambda_{\text {lvmhv }}$ & Adjusted $R^{2}$ & $\begin{array}{l}F \text {-statis } \\
\text { value) }\end{array}$ & \\
\hline Fourfo & & & & & & & & & & \\
\hline$M C$ & Mean & 0.041 & -0.012 & 0.003 & & 0.008 & -0.005 & 98.9 & 22.012 & 0.158 \\
\hline & SD & 0.319 & 0.168 & 0.041 & & 0.033 & 0.025 & & & \\
\hline & T-statistics & 1.252 & -0.712 & 0.811 & & $2.264^{*}$ & -2.017 & & & \\
\hline $\mathrm{PB}$ & Mean & 0.065 & -0.025 & 0.001 & & 0.001 & 0.001 & 66.2 & 0.490 & 0.774 \\
\hline & SD & 0.458 & 0.239 & 0.008 & & 0.012 & 0.083 & & & \\
\hline & $T$-statistics & 1.393 & -1.033 & 0.965 & & 0.511 & 0.106 & & & \\
\hline IVOL & Mean & -0.005 & 0.011 & -0.002 & & 0.000 & -0.001 & 44.8 & 0.203 & 0.910 \\
\hline & SD & 0.842 & 0.423 & 0.070 & & 0.048 & 0.012 & & & \\
\hline & $T$-statistics & -0.053 & 0.243 & -0.330 & & -0.042 & -0.585 & & & \\
\hline
\end{tabular}

*Significant at $5 \%$ level 

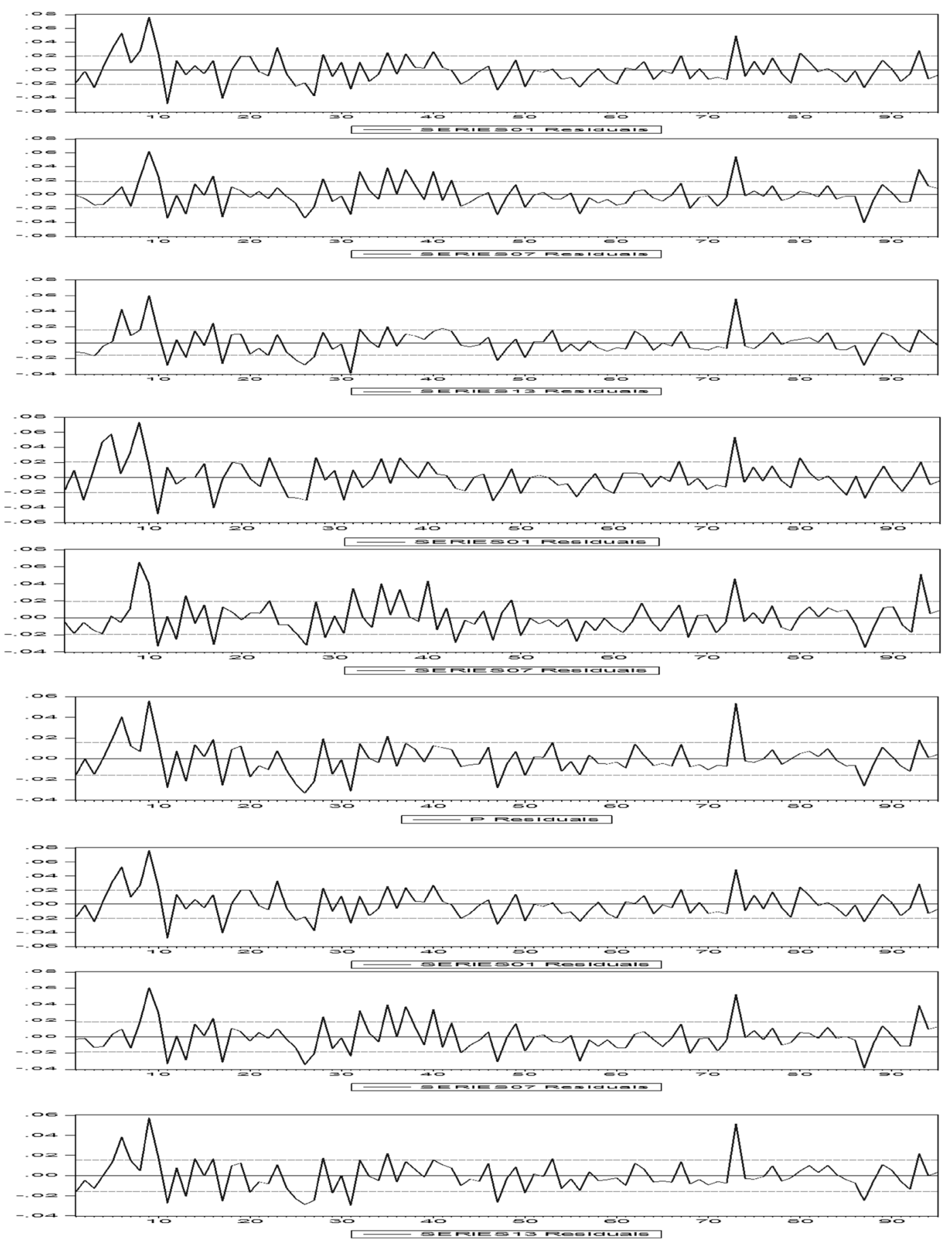

Fig. 2 Residual graphs for Fama-French's three-factor, three factor with idiosyncratic volatility and four-factor model of first portfolio (P11)

Di Iorio [37] findings in Australian context. Further Fama-MacBeth's cross-sectional regression, residual graphs and GRS test all confirm the superiority of fourfactor model over 2 three-factor models. Except PBbased portfolios, all other portfolios based on MC and
IVOL passes GRS model performance test for all the factor models used in the study.

The study findings imply that there is a high importance for considering idiosyncratic volatility risk factor while considering investment decision in the Colombo 
Table 9 Summary of GRS test results for all the factor models

\begin{tabular}{|c|c|c|c|c|c|}
\hline & GRS F-statistics & $P$ value & $\begin{array}{l}\text { Theta/thetas, proportion } \\
\text { of the potential efficiency }\end{array}$ & $\begin{array}{l}\text { Average absolute alpha } \\
\text { value }\end{array}$ & Average $R^{2}(\%)$ \\
\hline \multicolumn{6}{|c|}{ Fama-French three factor } \\
\hline MC & 0.746 & 0.614 & 0.826 & 0.003 & 97.1 \\
\hline $\mathrm{PB}^{*}$ & 2.371 & 0.036 & 0.635 & 0.003 & 97.1 \\
\hline IVOL & 1.153 & 0.339 & 0.762 & 0.003 & 97.0 \\
\hline \multicolumn{6}{|c|}{ Three factors with idiosyncratic volatility } \\
\hline$M C$ & 0.710 & 0.642 & 0.839 & 0.003 & 97.1 \\
\hline$P B^{*}$ & 2.617 & 0.022 & 0.626 & 0.003 & 96.9 \\
\hline IVOL & 1.095 & 0.372 & 0.779 & 0.003 & 97.1 \\
\hline \multicolumn{6}{|c|}{ Four factors } \\
\hline$M C$ & 0.732 & 0.625 & 0.835 & 0.003 & 97.2 \\
\hline$P B^{*}$ & 2.627 & 0.022 & 0.625 & 0.003 & 97.1 \\
\hline IVOL & 1.144 & 0.344 & 0.772 & 0.003 & 97.1 \\
\hline
\end{tabular}

*Significant at $5 \%$ level

stock exchange. Idiosyncratic volatility relationship to the portfolio expected returns is highly dependent on the portfolio construction factor variables. It is advisable not to form portfolios completely based on the $P / B$ ratio of the stocks as it may leads to higher risk. Further study results imply that investment decision on Colombo stock exchange should not be solemnly based on the time series analysis, but one must also consider cross-sectional analysis or both for high precisions. Finally, study concludes that idiosyncratic volatility is an equally important factor similar to market, size and value factors in pricing Colombo stock exchange for the study sample period. The study findings are in line with Liu and Di Iorio [37] findings in Australian context. Hence, investor should compensate for holding idiosyncratic risk stocks in the portfolio.

\section{Abbreviations}

MC: market capitalisation; Rf: risk-free rate; SMB: size; LMH: value; IVOL: idiosyncratic volatility.

\section{Acknowledgements}

Not applicable.

\section{Authors' contributions}

Complete work. The author read and approved the final manuscript.

\section{Authors' information}

Dr. Maiti is Associate Professor in the Department of Finance, and Research Fellow in the International Laboratory of Intangible-Driven Economy, National Research University Higher School of Economics, Saint-Petersburg. He teaches EPAS- and ACCA-accredited Master Courses in Finance and CIMA-accredited Bachelor courses. He is an active speaker and was invited to share the Worldrenowned platforms of World Bank, United Nations, World Trade Organisation (WTO Studies), SAS ${ }^{\circledR}$, Bloomberg LP, Max Plank Society, PEP Canada, Ivy League Universities, and many others. He was awarded with several notable academic and other awards throughout in his timeline. Several research grants from World-renowned institutions like World Bank, Max Plank Society
Germany, PEP Canada, World Trade Organisation (WTO Studies), Ivy League Universities and others are added to his account. He is an Associate editor of the Journal of the Geographical Institute "Jovan Cvijić" SASA, Serbian Academic of Sciences and Arts, Belgrade and Editorial board members of the journals: Business Strategy and Development, Wiley Publications, Journal of Asian Business and Economic Studies, Emerald Publications and Indian Journal of Finance. His articles are regularly published as research articles, book chapters, cases, blogs, and reviews, etc., by renowned publishing house.

\section{Funding}

Not applicable.

\section{Availability of data and materials}

The datasets used and/or analysed during the current study are available from the corresponding author on reasonable request.

\section{Competing interests}

The author declares that he has no competing interests.

Received: 31 July 2019 Accepted: 12 November 2019

Published online: 04 December 2019

\section{References}

1. Sharpe WF (1964) Capital asset prices: a theory of market equilibrium under conditions of risk. J Finance 19:425-442

2. Lintner J (1965) The valuation of risk assets and the selection of risky investments in stock portfolios and capital budgets. Rev Econ Stat 47:13-37

3. Mossin J (1966) Equilibrium in a capital asset market. Econom J Econom Soc 34(4):768-783

4. Merton RC (1987) A simple model of capital market equilibrium with incomplete information. J Finance 42:483-510

5. Malkiel BG, Xu Y (1997) Risk and return revisited. J Portf Manag 23:9-14

6. Malkiel BG, Xu Y (2006) Idiosyncratic risk and security returns. Working paper, The University of Texas at Dallas. Available at: https://www.utdallas. edu/ yexiaoxu/IVOT_H.PDF. Accessed Feb 2019

7. Goyal A, Santa-Clara P (2003) Idiosyncratic risk matters! J Finance 58:975-1007

8. Fu F (2009) Idiosyncratic risk and the cross-section of expected stock returns. J Financ Econ 91:24-37

9. Ang A, Hodrick RJ, Xing Y et al (2006) The cross section of volatility and expected returns. J Finance 61:259-299 
10. Ang A, Hodrick RJ, Xing Y et al (2009) High idiosyncratic volatility and low returns: international and further US evidence. J Financ Econ 91:1-23

11. Guo H, Savickas R (2010) Relation between time-series and crosssectional effects of idiosyncratic variance on stock returns. J Bank Finance 34:1637-1649

12. Frieder L, Jiang GJ (2008) Separating up from down: new evidence on the idiosyncratic volatility-return relation. American Finance Association Meetings, New Orleans. Available at SSRN: http://ssrn.com/abstr act $=970875$. Accessed Feb 2019

13. Chua CT, Goh J, Zhang Z (2006) Idiosyncratic volatility matters for the cross-section of returns-in more ways than one. Unpublished working paper, Singapore Management University

14. Wagner N, Winter E (2013) A new family of equity style indices and mutual fund performance: do liquidity and idiosyncratic risk matter? J Empir Finance 21:69-85

15. Blackrock (2011) Are emerging markets the next developed markets? BlackRock Investement Institute report. https://pdfs.semanticscholar.org/ e40d/03f424ed1338f71228ea1c8a167035616993.pdf. Accessed Feb 2019

16. Bali TG, Cakici N, Yan X et al (2005) Does idiosyncratic risk really matter? J Finance 60:905-929

17. Fama E, French K (1993) Common risk factors in the returns on stocks and bonds. J Financ Econ 33:3-56

18. Black F, Scholes M (1973) The pricing of options and corporate liabilities. J Polit Econ 81(3):637-654

19. Banz RW (1981) The relationship between return and market value of common stocks. J Financ Econ 9(1):3-18

20. Reinganum MR (1981) Misspecification of capital asset pricing: empirical anomalies based on earnings'yields and market values. J Financ Econ 9(1):19-46

21. Gibbons MR (1982) Multivariate tests of financial models: a new approach. J Financ Econom 10(1):3-27

22. Basu S (1983) The relationship between earnings yield, market value, and return for NYSE common stocks: further evidence. J Financ Econ 12:129-156

23. Bhandari LC (1988) Debt/equity ratio and expected common stock returns: empirical evidence. J Finance 43(2):507-528

24. Ross SA (1976) The arbitrage theory of capital asset pricing. J Econ Theory 13(3):341-360

25. Balakrishnan A, Maiti M (2017) Dynamics of size and value factors in stock returns: evidence from India. Indian J Finance 11:21-35. https://doi. org/10.17010/ijf/2017/v11i6/115593
26. Balakrishnan A, Maiti M, Panda P (2018) Test of five-factor asset pricing model in India. Vision 22(2):153-162

27. Maiti M, Balakrishnan A (2018) Is human capital the sixth factor? J Econ Stud 45(4):710-737

28. Maiti M (2019) Can leverage effect coexist with value effect? IIMB Manag Rev. https://doi.org/10.1016/j.iimb.2019.07.011

29. Maiti M (2019) OLS versus quantile regression in extreme distributions. Contaduría y administración 64(2):12

30. Maiti M (2018) A six factor asset pricing model. http://hdl.hand e.net/10603/257097. Accessed Oct 2019

31. Campbell JY, Lettau M, Malkiel BG et al (2001) Have individual stocks become more volatile? An empirical exploration of idiosyncratic risk. J Finance 56:1-43

32. Jiang $X$, Lee BS (2006) The dynamic relation between returns and idiosyncratic volatility. Financ Manag 35(2):43-65

33. Drew ME, Marsden A, Veeraraghavan M (2007) Does idiosyncratic volatility matter? New Zealand evidence. Rev Pac Basin Financ Markets Policies 10(03):289-308

34. Huang W, Liu Q, Rhee SG, Zhang L (2009) Return reversals, idiosyncratic risk, and expected returns. Rev Financ Stud 23(1):147-168

35. Zaremba A (2016) Is there a low-risk anomaly across countries? Eurasian Econ Rev 6(1):45-65

36. Peterson D, Smedeman AR (2011) The return impact of realized and expected idiosyncratic volatility. J Bank Finance 35:2547-2558

37. Liu B, Di lorio A (2016) The pricing of idiosyncratic volatility: an Australian study. Aust J Manag 41(2):353-375

38. Statman M (1987) How many stocks make a diversified portfolio? J Financ Quant Anal 22:353-363

39. Fama E, MacBeth J (1973) Risk, return and equilibrium: empirical tests. J Polit Econ 81:607-636

40. Gibbons MR, Ross SA, Shanken J (1989) A test of the efficiency of a given portfolio. Econom J Econom Soc 57(5):1121-1152

\section{Publisher's Note}

Springer Nature remains neutral with regard to jurisdictional claims in published maps and institutional affiliations.

\section{Submit your manuscript to a SpringerOpen ${ }^{\circ}$ journal and benefit from:}

- Convenient online submission

- Rigorous peer review

- Open access: articles freely available online

- High visibility within the field

- Retaining the copyright to your article

Submit your next manuscript at $\boldsymbol{\nabla}$ springeropen.com 